\title{
SOUZA, Marcos Santana de. 2012. A violência da ordem: polícia e representações sociais
}

\section{Pedro Martins}

\section{(2) OpenEdition \\ 1 Journals}

Edição electrónica

URL: http://journals.openedition.org/aa/1231

DOI: 10.4000/aa.1231

ISSN: 2357-738X

Editora

Programa de Pós-Graduação em Antropologia Social (UnB)

\section{Edição impressa}

Data de publição: 1 dezembro 2014

Paginação: 339-343

ISSN: 0102-4302

\section{Refêrencia eletrónica}

Pedro Martins, «SOUZA, Marcos Santana de. 2012. A violência da ordem: polícia e representações sociais», Anuário Antropológico [Online], v.39 n.2 | 2014, posto online no dia 01 agosto 2017, consultado o 28 abril 2021. URL: http://journals.openedition.org/aa/1231 ; DOI: https://doi.org/10.4000/aa.1231

\section{(c) $)(1)(9$}

Anuário Antropológico is licensed under a Creative Commons Atribuição-Uso Não-Comercial-Proibição de realização de Obras Derivadas 4.0 International. 


\section{SOUZA, Marcos Santana de. 2012. A violência da ordem: polícia e representações sociais. São Paulo: Annablume. 294 pp.}

Pedro Martins

UDESC

A década de 1980 caracterizou-se como uma época de grandes transformações. No plano mundial, a revolução da informática e o processo de globalização davam o tom das mudanças em curso, enquanto no plano nacional o processo de redemocratização alterava drasticamente as feições da república. É nesse cenário que se desenrola a narrativa de Marcos Santana de Souza, no esforço de compor um retrato da Polícia Militar (PM) do estado de Sergipe com seus desafios e dilemas contemporâneos. Doutor em ciências sociais pela Universidade Estadual de Campinas (Unicamp) e professor da Universidade Federal de Sergipe (UFS), Souza é historiador de formação e apresenta esse texto originalmente como dissertação de mestrado em ciências sociais na UFS, tratando de incorporar ao estudo seus seis anos de experiência como policial militar - função que exerceu desde a graduação até a conclusão do mestrado.

$\mathrm{Na}$ expectativa de prevenir-se do conflito entre a sua condição de pesquisador de uma instituição policial e sua realidade de policial militar na mesma instituição, o autor trata de elaborar uma sólida reflexão sobre o eventual viés perante o potencial efeito positivo de uma visão de dentro da organização pesquisada. Essa reflexão, repleta de conhecimentos empíricos obtidos na caserna, precede a própria introdução ao trabalho e prepara o espírito do leitor, deixando às claras as condições de elaboração da pesquisa. Seu ingresso como soldado na PM, na condição de estudante universitário, destoa de uma realidade em que o posto era normalmente ocupado por candidatos de pouca instrução formal, seguindo, na época, uma tendência verificada a partir do final dos anos 1990, que levou estados como Santa Catarina a exigirem curso de graduação aos postulantes ao cargo. Para o autor, se a proximidade com o objeto de estudo pode ser perigosa, o conhecimento empírico prévio possibilitou a problematização da questão e a elaboração do problema de pesquisa - que o conduziu de volta ao estranhamento.

O texto propõe-se a comparar a realidade dos anos 1980 e a atualidade, tendo em vista que o ponto de partida representa um divisor de águas marcado, no Brasil, pelo fim da ditadura militar e a eclosão do processo de globalização 
moderna. O corpo do trabalho está estruturado em três capítulos, partindo da reflexão mais ampla em direção à especificidade da organização militar em apreço.

No primeiro capítulo, "Estado e violência", o autor apresenta o estado da arte das pesquisas e reflexões sobre o tema. Resgatando a dialética entre o local e o global, mostra como a modernidade se exprime na questão da violência. Resgata fenômenos como os conflitos entre jovens e polícia nos subúrbios da Inglaterra e França, aos quais se pode comparar os ataques a ônibus e instalações públicas em Santa Catarina por facções do crime organizado em 2012 e 2013.

Ainda nesse capítulo, Souza traz à tona a concepção de Anthony Giddens de segurança ontológica, sentimento que marca a ordem tradicional e que paulatinamente vai se quebrando e dando espaço à percepção da insegurança. Passa-se assim ao aumento da violência não como fato, mas como percepção. É na década de 1980 que acontece a transição dos processos costumeiros para os processos jurídicos. Questões antes resolvidas "na conversa” tornam-se "casos de polícia" e a judicialização da vida cotidiana traz como consequências o sentimento de insegurança e o aumento das demandas nesse campo em relação ao Estado. Dialogando com Zygmunt Bauman, o autor afirma que, diante da ideia de risco iminente, a segurança se torna prioridade, inclusive, sobre a liberdade de expressão e outros direitos fundamentais. Resgata, assim, a gênese das forças policiais mostrando que esses instrumentos de exercício da força por parte do Estado utilizam expedientes de guerra nas questões de segurança pública, fazendo com que a resposta do Estado à percepção de insegurança por parte do cidadão gere ainda mais insegurança - especialmente entre os integrantes dos grupos subalternos.

Nos últimos anos — depreende-se do diálogo com Zaluar —, o crime organizado tem se aparelhado ao mesmo tempo em que cresce o espectro das empresas de segurança privada. Isso impede cada vez mais o Estado de monopolizar os meios de violência no país e, assim, defender os grupos em condição de fragilidade dos que têm condições de se armar. O autor avança na compreensão do conjunto de contradições internas das polícias, da relação entre a existência de crime e a necessidade de segurança, para buscar a origem de um quadro de violência que resiste às iniciativas do Estado e, com isso, apontar para as contradições internas do seu objeto de estudo, a Polícia Militar de Sergipe.

No segundo capítulo, “Da 'guerra da maconha' ao extermínio de meninos: violência e segurança pública nos anos 1980 em Sergipe”, o autor traz um minucioso levantamento de notícias publicadas na imprensa, especialmente em jornais impressos, que ajudam a compor um mosaico da ação policial no início Anuário Antropológico/2013, Brasília, UnB, 2014, v. 39, n. 2: 339-342 
da década de 1980 no estado e, assim, delinear um perfil da própria polícia no período. Com calma e sem pressa, Souza constrói uma narrativa, buscando contextualizá-la e localizá-la no tempo e no espaço, sempre numa perspectiva diacrônica.

O autor destaca o movimento de adaptação da polícia militar e de outras forças de segurança ao novo cenário político nacional, marcado pela transição da ditadura cívico-militar para o estado de direito. Mostra como a Doutrina de Segurança Nacional tem um efeito perverso sobre a formação das forças de segurança, efeito que se revela em suas idiossincrasias. Afirma que "[...] os anos finais da ditadura ficariam marcados pelo aumento vertiginoso da violência e pela continuidade dos métodos autoritários das instituições policiais, com o reforço da militarização do campo da Segurança Pública em Sergipe” (:98).

Dialogando com Boaventura Souza Santos, Souza mostra que, no mesmo período, nos países desenvolvidos, as desigualdades sociais e os processos de exclusão se agravaram. Nos países periféricos, caso do Brasil, nota-se o aumento da dívida externa e outros mecanismos de dependência que agravam a violência interna. Nessa década (1980), o "[...] desenvolvimento social e econômico do Estado está associado à ampliação das desigualdades sociais e concomitantemente à emergência da violência como uma das principais pautas da agenda social e política" (:102).

O outrora romântico tráfico de drogas adquire aspectos dramáticos nos anos 1980, constata o autor. Essas mudanças, globais e locais, acompanham a consolidação das forças policiais cujos efetivos, nos anos seguintes, serão drasticamente ampliados. A maior demanda por ordem resulta em um esforço para aumentar o efetivo policial — ainda que não denote uma correlação direta. O crescimento da violência e o envolvimento de policiais em ações ilegais, continua o raciocínio do autor, corroeram a imagem dos policiais e ajudaram a estabelecer conflitos com a sociedade civil. Souza narra casos de violência policial contra pobres e negros, criminosos ou apenas suspeitos. Analisa também o comportamento da imprensa em relação à postura da polícia, mostrando que, via de regra, os meios de comunicação simpatizam com a postura truculenta e discriminatória.

O fim da década de 1980, destaca o autor, marca o ingresso das primeiras mulheres nos quadros da PM de Sergipe. Mas registra ainda uma grande contradição: a presença de comandantes egressos do Exército, o que enfatiza o caráter militar da PM em oposição às expectativas de uma polícia cidadã. Registra o autor que, nos primeiros cem anos de existência da PM do estado, dos 50 comandantes, 31 eram oriundos dos quadros do Exército e apenas 19 dos quadros da própria PM. 
No terceiro capítulo, "Policiais militares em sua realidade subjetiva: representações identitárias e representações da violência”, o autor propõe-se a "analisar a realidade social subjetiva de um grupo de policiais militares" (:156), buscando entender os "processos sociais da violência policial". Para atingir o propósito, levanta as representações dos sujeitos em relação à sua identidade, à sua realidade social e à violência. Busca, assim, desvendar o sentido da violência policial. Trata-se de um objetivo ambicioso e metodologicamente complicado, apesar da facilidade de acesso do pesquisador às fontes.

Com muita criatividade e alguma licença poética, Souza percorre um caminho pontilhado por depoimentos e referências bibliográficas em busca da construção de conceitos de percepção, representação e identidade. Infere, do sentimento manifesto pelos policiais, que sua identidade é marcada pela percepção de que a sociedade não lhes reconhece o valor. Desvenda o conflito de uma identidade vinculada ao Exército ao mesmo tempo em que o sentimento de dever exige que o policial esteja mais próximo do cidadão. Essa contradição, por vezes, manifesta-se no cotidiano do quartel e representa impasses nem sempre superados a contento - o que leva a uma crise de identidade.

No plano das representações, o autor revela a condição estigmatizada dos policiais, que relacionam a má imagem da PM à sua associação com a ditadura. Revelam, assim, a sua fragilidade humana e sua preocupação com a imagem construída pela sociedade, o conflito com outras forças policiais e o problema das relações de gênero no interior do quartel — diferenças que, segundo o autor, estão longe de ser equacionadas.

No campo da produção nacional sobre o tema, a obra traz uma importante contribuição. Ainda que muitos trabalhos específicos tenham aparecido nos últimos tempos, o estudo de conjunturas locais tem muito a acrescentar na compreensão do problema. De qualquer forma, as mudanças cada vez mais rápidas e drásticas na realidade social do país apontam para a necessidade premente de desvendar os tortuosos caminhos da segurança cidadã para reverter o quadro de violências que assombram a sociedade. Nesse sentido, o livro de Marcos Santana de Souza aparece como alento. 